\title{
Actual evapotranspiration estimation in the upper reaches of the Jinghe River basin with the Advection-Aridity model
}

\author{
S.Z. DANG, G.T. DONG, F.R. ZHANG, K. DU \\ Yellow River Institute of Hydraulic Research, Yellow River Conservancy Commission, Zhengzhou \\ 450003, China
}

\begin{abstract}
KEYWORD: Evapotranspiration; Complementary Relationship; AA model; the Jinghe River ABSTRACT: Evapotranspiration is the largest component of water loss from storage and has a major influence on all hydrological processes. Based on meteological and hydrological in the upper reaches of the Jinghe River basin, Advection-Aridity model was applied to estimate the actual evapotranspiration from 1966 to 2012. The results showed that the average annual actual evapotranspiration is $529.4 \mathrm{~mm}$ in the study area, and the variation of actual evapotranspiration was described as four phases. Model calculation results can reflect the regional evapotranspiration loss and provide the basis for the regional soil moisture and green water analysis.
\end{abstract}

\section{INTRODUCTION}

Evapotranspiration is a key process within the Earth's surface water and energy balance. The concept of the complementary relationship between actual and potential evapotranspiration proposed by Bouchet (1963) provides a new way of calculating regional evapotranspiration. The most widely known models based on the hypothesis of the complementary relationship are the Advection-Aridity (AA) model (Brutsaert and striker, 1979), Complementary Relationship Areal Evapotranspiration (CARE) model (Morton, 1983) and the Granger and Gray (GG) model (Granger, 1989). The advantages of these models are that they estimate actual evaportanspiration from observations of the overpassing air without the requirement for factors or assumptions associated with the soil-vegetation system (Xu, 2005). Using the meteorological and hydrological data in the Yellow River basin, combined with satellite remote sensing information and digital elevation model, the AA, CARE, and GG models were applied to evaluate the calculation precision in different time scales and climate zones, and the results showed the estimated monthly actual evapotranspiration from AA model was more reasonable and perfectly(Liu, 2004). The Advection-Aridity (AA) model was selected in this study to estimate actual evapotranspiration in the upper reaches of Jinghe River basin, this study also aims to character the change in actual evapotranspiration in the study area from 1966 to 2012.

\section{STUDY AREA AND DATA}

\section{Study area}

The Jinghe River is one of the top ten drainages in the Yellow River basin, located in the Loess Plateau in the northwestern China. The upper reaches of the Jinghe River basin $\left(106^{\circ} 11^{\prime} \sim 107^{\circ} 21^{\prime} \mathrm{E}\right.$, $35^{\circ} 15^{\prime} \sim 35^{\circ} 45^{\prime} \mathrm{N}$ ) occupies an area of $3164 \mathrm{~km}^{2}$, the highest land surface elevation is $2911 \mathrm{~m}$ of the Liupanshan mountain in the western part of the region, while the minimum altitude is $1100 \mathrm{~m}$. The annual mean temperature is $8.9^{\circ} \mathrm{C}$. The annual precipitation is about $586 \mathrm{~mm}$, as influenced by the monsoon climate, the precipitation is concentrated in the wet season, and the percentage of precipitation falling during June and September varies from $53 \%$ to $85 \%$.

\section{Data}

Daily meteorological records of 4 national meteological stations from 1966 to 2012 from the National Climatic Centre of the China Meteological Administration were used in this study (Fig. 1). The meteorological data included daily precipitation, maximum, minimum and mean air temperatures, wind speed, relative humidity, and sunshine duration. The monthly streamflow $(1973 \sim 2012)$ at the Jingchuan station and the monthly precipitation data at 34 rainfall gauges from 1966 to 2012 were provided by the Yellow River Hydrological Bureau (Fig. 1). 


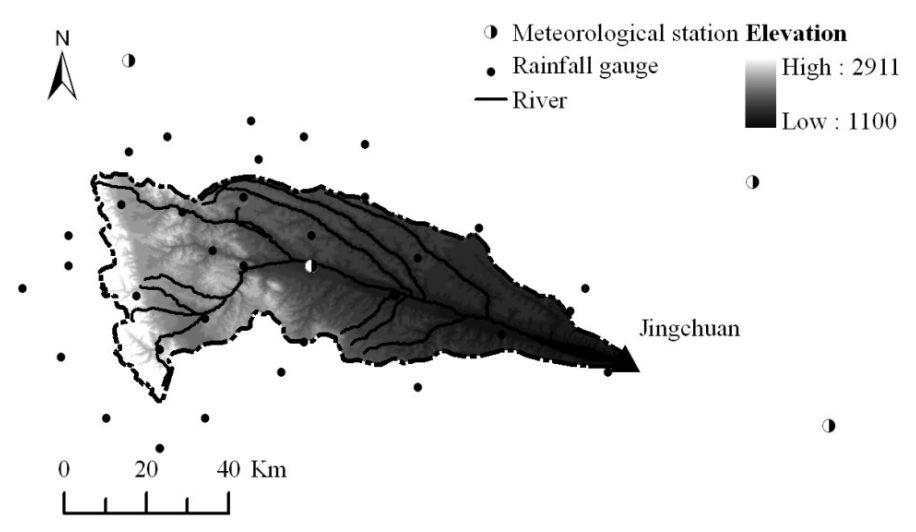

Figure 1. Map of the study area

\section{methodology}

\section{The complementary relationship hypothesis}

The concept of the complementary relationship between actual and potential evapotranspiration proposed by Bouchet (1963) states that over areas of a regional size and away from sharp environmental discontinuities, there exists a complementary feedback mechanism between actual ( $\left.E T_{a}\right)$ and potential evapotranspiration ( $E T_{p}$ ). This relationship can be expressed as

$$
d E T_{a}+d E T_{P}=0
$$

in which $E T_{a}$ is the actual evapotranspiration, $E T_{p}$ is the potential evapotranspiration, $d E T_{p}$ and $d E T_{a}$ are the changes in the potential evapotranspiration and the actual evapotranspiration caused by change in the availability of water. Eq. 1 states that the increased of $E T_{p}$ is equal to the decrease of $E T_{a}$.

Integrating Eq. 1, gives

$$
E T_{a}+E T_{P}=C
$$

Where $C$ is an integration constant, and can be estimated according to boundary conditions. In this context, $E T_{p}$ is defined as the evapotranspiration that would take place from a moist surface under the prevailing atmospheric conditions, limited only by the amount of available energy. Under conditions where $E T_{a}$ equals $E T_{p}$, this rate is referred to as the wet environment evapotranspiration $\left(E T_{w}\right)$. The general complementary relationship is then expressed as

$$
E T_{a}+E T_{P}=2 E T_{w}
$$

Where $E T_{w}$ is the wet environment evapotranspiration. As shown in Eq. 3, under dry conditions, there is no water supply from evapotranspiring surface, $E T_{a}=0$ and $E T_{p}=2 E T_{w}$; under wet conditions, $E T_{a}=E T_{p}$, that is the potential evapotranspiration in a completely humid area equals to the wet environment evapotranspiration. This provides the possibility of estimating the actual evapotranspiration from rountine climatological observations. This is done by computing potential evapotranspiration and wet environment evapotranspiration.

\section{AA model}

In this section the components of the complementary relationship are summarized for the AA model. In this model, $E T_{p}$ is calculated by the Penman equation which combines information from the energy budget and water vapor transfer, and $E T_{w}$ is calculated by the Priestly-Taylor equation based on derivations of the concept of equilibrium evapotranspiration under conditions of minimal 
adcection, first proposed by Priestly and Taylor (1972). The expressions for $E T_{p}, E T_{w}$ and $E T_{a}$ in AA model are shown as follows.

$$
\begin{aligned}
& E T_{P}=\frac{\Delta}{\Delta+\gamma} \frac{R_{n}}{\lambda}+\frac{\gamma}{\Delta+\gamma} e_{a} \\
& E T_{w}=\alpha \frac{\Delta}{\Delta+\gamma} \frac{R_{n}}{\lambda} \\
& E T_{a}=(2 \alpha-1) \frac{\Delta}{\Delta+\gamma} \frac{R_{n}}{\lambda}-\frac{\gamma}{\Delta+\gamma} e_{a}
\end{aligned}
$$

Where $R_{n}$ is the net available energy at the surface, $\lambda$ is the latent heat of vaporization, $\Delta$ represents the slope of the saturated vapor pressure curve at air temperature, $\gamma$ is the psychrometric constant, $e_{a}$ is known as the "drying power of the air", $\alpha$ is the Priestly and Taylor constant, an approximate value of $\alpha=1.26$ is suggested from Priestly and Taylor (1972) for water surfaces under condition of minimal advection and in the absence of inversions and condensation.

\section{Changing trend analyses}

(1) the non-parametric Mann-Kendall (MK) rank statistic method

To analyze the trend and test its significance for annual precipitation, potential evapotranspiration and runoff series, the non-parametric Mann-Kendall (MK) rank statistic method (Mann 1945; Kendall 1975) was applied. The Mann-Kendall test is suggested by the World Meteorological Organization, and has been widely used as an effective tool for analyzing the trends in meteorilogical and hydrological variables, such as water quality, temperature and precipitation (Hirsch and Slack et al. 1982; Liu and Zheng 2004; Xu and Takeuchi et al. 2005). It is robust to outliers and can be used to detect linear or nonlinear monotonic trends (Helsel and Hirsch 1997). The algorithm of MannKendall test is briefly introduced as follows.

For a time series $\mathrm{X}=\left\{x_{1}, x_{2}, \ldots, x_{n}\right\}$, where $n>10$, the standard normal statictic $Z_{C}$ is estimated as follows:

$$
Z_{c}= \begin{cases}(S-1) / \sqrt{\operatorname{var}(S)} & S>0 \\ 0 & S=0 \\ (S+1) / \sqrt{\operatorname{var}(S)} & S<0\end{cases}
$$

Where

$$
\begin{gathered}
S=\sum_{i=1}^{n-1} \sum_{j=i+1}^{n} \operatorname{sgn}\left(x_{j}-x_{i}\right) \\
\operatorname{sng}\left(x_{j}-x_{i}\right)=\left\{\begin{array}{l}
+1, x_{j}>x_{i} \\
0, x_{j}=x_{i} \\
-1, x_{j}<x_{i}
\end{array}\right. \\
\operatorname{Var}(S)=\frac{\left[n(n-1)(2 n+5)-\sum_{t} t(n-1)(2 t+5)\right]}{18}
\end{gathered}
$$

Where $x_{i}, x_{j}$ are the sequential data values, $\operatorname{sng}(\theta)$ is equal to $1,0,-1$ if $\theta$ is greater than, equal to, or less than zero, respectively, $t$ is the extent of any given tie and denotes the summation of all ties. A time series has a significant trend, if $\left|Z_{C}\right|>Z_{(1-\alpha / 2)}$, at a confidence level of $\alpha$. For example, at a $5 \%$ confidence level, $Z_{(1-\alpha / 2)}=1.96$, if $Z_{c}>1.96$ or $Z_{c}<-1.96$, it demonstrates that the null hypothe- 
sis of no trend is rejected. And further, a positive value of $Z_{c}$ indicates an increasing trend, and the negative value of $Z_{c}$ corresponds to a decreasing trend.

(2) Accumulated difference curve

The accumulated difference curve was also applied to analyze the runoff change (Hao and Chen et al. 2008). A downward gradient suggests a decreasing trend in runoff and vice versa, and a horizontal gradient indicates the runoff is approaching the average annual runoff. A continuous downward or upward gradient suggests that water deficiency or wet years has existed for a long period of time, respectively.

\section{Results}

The Priestly and Taylor constant $\alpha$ is associated with regional characteristics according to the results from Xu (2005), and can be further calibrated with the principle of water balance. The annual mean actual evapotranspiration is $518 \mathrm{~mm}$ according to the water balance equation using the measured runoff of Jingchuan hydrological station and precipitation data of 34 precipitation stations in and around the river basin. The value of $\alpha$ is the optimal value when the water balance closure error is zero, then the optimal value of $\alpha$ in AA model for the upper reaches of Jinghe river basin is 0.96.

The value of actual evapotranspiration was between $478.4 \mathrm{~mm}$ and $582.3 \mathrm{~mm}$ in the upper reaches of the Jinghe river from 1966 to 2012 as shown in Fig. 2, and the average annual actual evapotranspiration was $529.4 \mathrm{~mm}$. The maximum actual evapotranspiration occurred in 1968, while the minimum was in 1989.

In the upper reaches of Jinghe River basin, the actual evapotranspiration had a decreasing trend. The Mann-Kendall test result showed that the decreasing trend of annual actual evapotranspiration was not remarkable at the 0.05 significance level.

The accumulated difference curve of actual evapotranspiration in the study area showed that it underwent four stages (Fig. 3), an increasing trend between 1966 and 1978, and a subsequent decrease trend from 1979 to 1992 , then an increasing trend from 1993 to 2006, and a subsequent decrease trend between 2007 and 2012. When the accumulated difference curve showed an increase trend, the actual evapotranspiration in this period was larger than the average annual actual evapotranspiration; vice versa, the actual evapotranspiration is smaller than the average annual actual evapotranspiration when the accumulated difference curve had a decrease trend. Then we can see that the actual evapotranspiration was larger than the average annual value for the two periods from 1966 to 1978 and from 1993 to 2006, and it was smaller in the periods from 1979 to 1992 and 2007 to 2012.

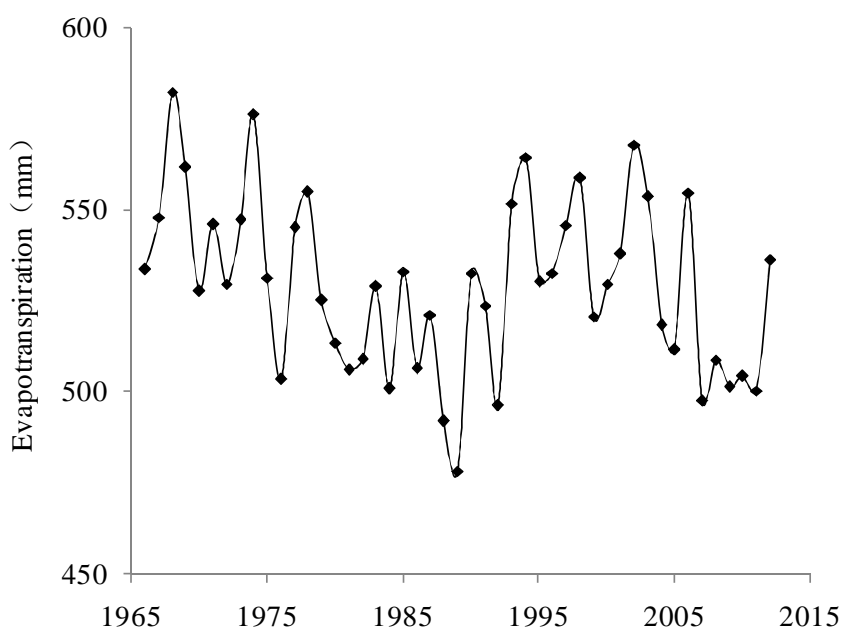

Figure 2. Variation of the actual evapotranspiration in the study area from 1966 to 2012. 


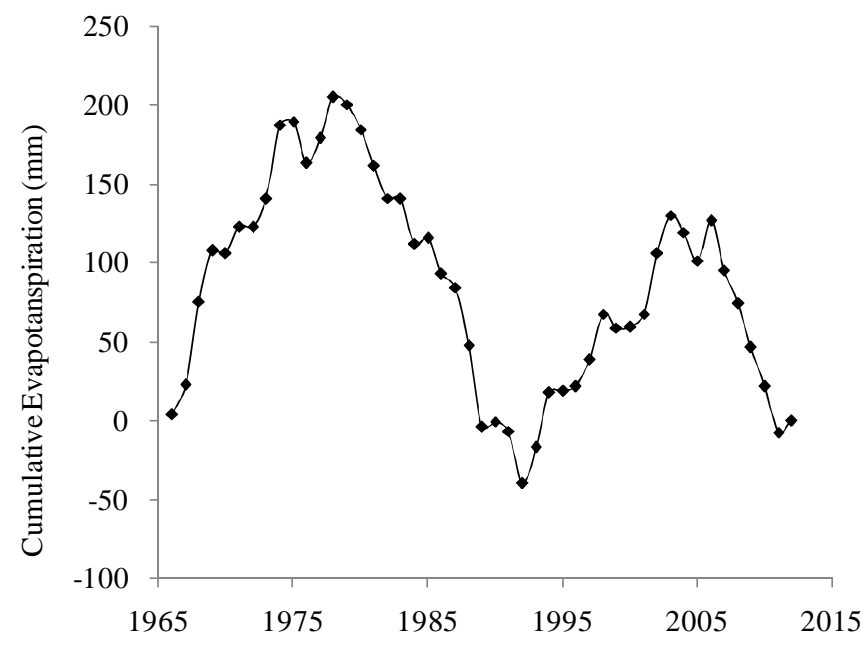

Figure 3. Accumulated difference curve of the actual evapotranspiration from 1966 to 2012.

\section{conclusions}

It is shown that the Advection-Aridity model can be applied in the upper reaches of Jinghe river ba$\mathrm{sin}$, and the estimated average annual actual evapotranspiration is $529.4 \mathrm{~mm}$. The variation of actual evapotranspiration was described as four phases, it had an increasing trend during the two periods from 1966 to 1978 and from 1993 to 2006, while in the periods from 1979 to 1992 and 2007 to 2012, it had a decreasing trend.

\section{Acknowledgments}

This work was carried out with the support of the National Natural Science Foundation of China (Grant No.41301030; 41301496; 91325201).

\section{References}

[1] Bouchet R J, Evapotranspiration reele et potentielle, signification climatique[J]. General Assembly Berkeley, Int Ass Sci Hydrol,1963,62: 134-142.

[2] Brutsaert W, Stricker H, An advection-aridity approach to estimate actural regional evapotranspiration[J]. Water Resource Research, 1979, 15(2): 443-449.

[3] Morton F. I., Operational estimates of areal evapotranspiration and their significance to the science and practice of hydrology[J]. Journal of Hydrology, 1983, 66:1-76.

[4] Granger R J, Gray D M, Evaporation from natural no-saturated surfaces[J]. Journal of Hydrology, 1989, 111: 21-29.

[5] Xu Chongyu, Singh V P, Evaluation of complementary relationship evapotranspiration models by water balance approach to estimate actual regional evapotranspiration in different climatic regions [J]. Journal of Hydrology, 2005, 308: 105-121.

[6] Liu Shaomin, Sun Rui, Sun Zhongping, et. al., Comparison of different complementary relationship models for regional evapotranspiration estimation [J]. Acta Geographica Sinica, 2004, 59(3):331-340. (In Chinese)

[7] Priestley C H B, R J Taylor, On the assessment of surface heat flux and evaporation using largescale parameters[J]. Monthly Weather Review, 1972, 100(2): 81-92.

[8] Mann, H. Nonparametric tests against trend. Econometrica, 1945, 13: 245-259.

[9] Kendall, M. Rand correlation methods. Charles Griffin: London, UK, 1975; Volume 202.

[10]Hirsch, R., J. Slack, et al. Techniques of trend analysis for monthly water quality data. Water Resources Research, 1982, 18(1): 107-121. 
[11]Liu, C. and H. Zheng. Changes in components of the hydrological cycle in the Yellow River basin during the second half of the 20th century. Hydrological Process, 2004, 18(12): 2337-2345.

[12]Xu, Z., K. Takeuchi, et al. Long-term trend analysis for precipittion in Asian Pacific FRIEND river basins. Hydrological Process, 2005, 19(18): 3517-3532.

[13]Hao, X., Y. Chen, et al. Impacts of Climate Change and Human Activities on the Surface Runoff in the Tarim River Basin over the Last Fifty Years. Water Resources Management, 2008, 22(9): 1159-1171. 